\section{United front on basic research}

\section{Washington}

THE mutual congratulations of the National Science Foundation (NSF) and its authorization committee, the House of Representatives subcommittee on science, research and technology, at their first encounter of the budget season last week, were soured only by Representative Ted Wirth's (Republican, Colorado) attempt to find out why Colorado State University has not become a supercomputer centre. According to Erich Bloch, NSF's director, the explanation is simple: Colorado State was one of 22 competitors for the honour, but its application was simply not good enough to be one of the five chosen under Phase II of NSF's programme to build an academic supercomputer network. Bloch's scorn of the pork-barrel is well known, but the primness of his rejection of the taint last week may have been undiplomatically austere.

The issue of Colorado State's computer centre is a tiny cloud in what seems to be an otherwise clear sky. The university became part of Phase I of the programme in 1984, with the gift of a Cyber 205 machine from NSF, but this did not qualify it to become one of the five Phase II centres, on which NSF will be spending $\$ 35.5$ million next financial year if the budget survives. But is this not a waste of taxpayers' money? Wirth's simple question was simply answered with the information that supermachines are cheaper now than two years ago. Whether this will satisfy Colorado State and Wirth remains to be seen.

For the rest, only mutual uncertainty about this year's budget process, "meat cleaver" accountancy according to one committee member, disturbs the cosiness of the subcommittee's relationship with its only charge. But Bloch, careful as always, failed to seize the opportunity of saying which programmes NSF would have to butcher when the Gramm-Rudman axe falls compulsorily if the federal budget exceeds the legal limit later in the year. Bloch said only that NSF had been able to survive this year's cut of 4.3 per cent by selective economies in NSF's different programmes. This would not be possible if, later in the year, the Gramm - Rudman legislation should make cuts of " 10,15 or even 20 per cent" from next year's spending plans.

NSF is being dealt with even-handedly but not generously at this stage. The budget is due to rise by 8.4 per cent to a total of $\$ 1,686$ million in the financial year beginning on 1 October (see Nature 319, $526 ; 1986$ ). Bloch pointed out last week that research and development supported by the federal government is due to increase even faster, with the result that basic research will be a shrinking pro- portion of the cost of federally supported development (almost all of which is military). "The already small share of research dollars devoted to basic research is dropping."

The subcommittee and the agency it superintends appear this year to be more determined than ever to carry a torch for basic research. With economic competition internationally, persistent unemployment, budget deficits and a "faltering educational system", what could be more important than NSF and its support of basic research?" asked one committee member. Dr Roland W. Schmitt, the chairman of the National Science Board, NSF's policy-making partner, equally asserts that the academic system "is the basis of the economic defense" of the United States.

So how could NSF and the board remedy the "under-investment" in basic research in the United States? Both agreed that they cannot succeed alone. NSF spends less than a fifth of federal spending on basic research, which itself is only 14 per cent of government spending on research and development of all kinds. But Bloch and Schmitt agree on their objectives.

One need is to persuade other government agencies to pay more attention to

\section{Tokyo}

THE Japanese government has been dropping broad hints that it will soon allow participation in the US Strategic Defense Initiative (SDI). Whether the hints are partly intended as trial balloons to see whether opposition remains is unclear, but they have been sufficient to draw a strongly worded warning from the official Soviet news agency Tass.

The government appears to have abandoned thoughts of participating directly in the SDI project through research in its own institutes. Instead, private industry will be allowed to accept contracts for SDI research. A final decision is likely to be announced before the annual summit of seven industrial nations in Tokyo in May.

A year has already passed since the United States invited Japan to participate in SDI, without the government having been able to come to a decision. Early on, obstacles were seen to participation in Japan's bans on weapons exports and on nuclear weapons research. But supporters of SDI within the government argue that joint research and development is different from arms exports and that even if nuclear energy is used in SDI, to pump X-ray lasers for example, that does not make them nuclear

their own self-interest in the well-being of basic research. The condition of the universities, and especially of their equipment, needs attention. The declining numbers of US citizens going on to $\mathrm{PhD}$ courses is alarming. (Schmitt says that his experience, from a base at General Electric, is that many industrial laboratories would be "in deep trouble" if one half of the overseas $\mathrm{PhD}$ graduates did not stay on in the United States.) So more energetic steps must be taken to capture the enthusiasm of young people at an early stage, whence the renewed interest and spending of school curriculum development.

For the year immediately ahead, NSF plans to spend more on its academically based engineering centres, of which there are already six, with another four or five about to be announced and with funds for a further four in next year's budget. Extra funds will be found for biotechnology (in which there is now a plant sciences postdoctoral programme), computational science and "global geoscience" (where spending will be increased by $\$ 18$ million, compared with $\$ 17$ million in the present year).

That is what will happen if the budget survives. In the subcommittee's mood last week, it will not rob NSF of a single cent. But nobody can guess at this stage how far the committee's protection of its protegee will be undermined by Gramm-Rudman.

John Maddox

\title{
Japan likely to participate in SDI
}

weapons. Fear of arousing public opposition has, however, made the government very cautious. Two missions have visited the United States to seek further information and a third, which will contain business leaders as well as government representatives, is likely to be despatched in the near future.

Japanese corporations are mainly concerned that they might be left behind in the "technological dust" if they do not participate in SDI. Nor do they wish to miss access to the huge sums of money that are likely to be spent in the research phase of SDI. But there is also a strong awareness that Japan's own great economic success is not entirely unrelated to high expenditure on commercial development research and tiny expenditure on military research. For that reason, industry is keen to maintain a position in which the results of SDI research can be easily transferred to the commercial sector. But that position may not necessarily work to industry's advantage. Although under present Japanese law it would be hard to stop such transfer, it is likely that few contracts will come Japan's way unless legal protection of "military secrets" can be strengthened.

Alun Anderson 